\title{
Bridging the divide: Making research matter to local government
}

\section{Commonwealth Journal of Local Governance}

Special Issue March 2010:

Commonwealth Local Government Conference

Freeport, Bahamas, May 2009

http://epress.lib.uts.edu.au/ojs/index.php/cjlg

\section{Mark Redwood}

Program Leader, Urban Poverty and Environment International Development Research Centre, Canada

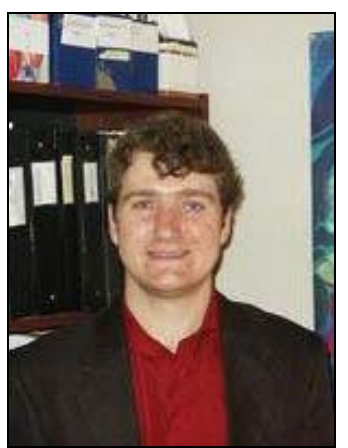

The 'Freeport Declaration on Improving Local Government: The Commonwealth Vision', affirmed at the May 2009 Commonwealth Local Government Conference by 550 councillors, mayors, and senior officials from 48 countries, outlined the clear importance of research in public policy development. In the words of the Declaration: "practice oriented research should become more prominent in the work of CLGF," and this is to be achieved through the Commonwealth Local Government Forum (CLGF) Research Advisory Group, comprised of participants drawn from universities, training organizations and other research-related bodies in about a dozen member countries. These statements should be the basis of a radical change in how researchers engage local governments.

Since 2005, Canada`s International Development Research Centre (IDRC) and the Urban Poverty and Environment Program has been working with communities of researchers linked to municipal governments in eight cities. One of their main objectives: trying to bridge the sometimes too large a gap between local government and the research community. Lessons from this experience suggest to us that a renewed effort to push for policy relevant research is required. The eight projects, collectively known as the Focus Cities Research Initiative (FCRI), have found that research can be highly valuable and 
widely utilized when it responds directly to local government needs. ${ }^{1}$ However, the program has also found that while there is broad agreement that evidence-based policy and programs are required to support local government decision making, in practice, the transfer of knowledge from researchers and scientists to governments and service deliverers is problematic and not always easily achieved.

The gravity of problems faced by local governments - frequently being on the front lines of service delivery - is stretching conventional models of governance. Examples of this are widespread and well known. For instance the pace of migration to cities is outpacing the ability of local governments to provide adequate basic services while land markets are excluding all but the richest in accessing adequate and secure housing. Compounding these problems is the fact that limited financial resources are available hindering the ability of local governments to respond. So, instead of focusing on long term resilience of their communities, local governments are all too frequently working from day-to-day and responding to various crises. The end result is that many constituents have lost faith in their representatives.

Most problems faced by communities are not technical in nature, but rather they reside in the institutional and behavioral realm. In some fast growing municipalities across the globe there exist many illegal settlements. Being illegal prevents proper services from being delivered. Given the complexity involved in regularizing settlements, some local governments take the easier route and just ignore them. This can have disastrous consequences. Since receiving municipal services typically depends on official recognition as a ratepayer, a lack of recognition means that entire communities have little hope of receiving sanitation, water, schooling, and other essential services. While this is a well-understood dynamic in the research literature, many governments still have not been able to change despite the plethora of material on what should be done. It is just as likely that the proposals offered by academics are not well understood or simply not feasible, as it is that the municipal government is not interested in reform. Another common challenge can be labeled the 'transformation mindset' of incoming elected officials who tend to want to dramatically change the work of their predecessors and to

\footnotetext{
1 The cities are Dakar, Moreno, Cochabamba, Colombo, Jakarta, Lima, Tunis and Kampala. Papers on the Colombo and Kampala projects are included in this issue of the Commonwealth Journal of Local Governance. For more information on the program, see Hwww.idrc.ca/upe
} 
do so quickly. This timeline can be out of sync with the methodical development of research, which takes time to do well.

It is also a fallacy to believe that money will always solve things. Yes, it is a critical factor, however, many quality governments work with very few financial resources - and usually this is because they are endowed with strong capacity in human resources. Moreover, some municipalities with very small budgets can do great things if they are allowed the freedom to do so. Researchers should thus endeavor to develop work that ties their research interests with the needs identified by their partners in local government. For example, research can highlight, compare and measure the effectiveness of service delivery alternatives.

Finally, the dearth of locally-derived and evidence-based guidelines for major policy direction is a serious problem that needs to be addressed. The water and sanitation sector is a good example of where standards developed for Northern countries are often applied with little realism in the contexts of many resource-poor countries. The WHO guidelines for wastewater use, for example, were for many years derived from EU and California standards.

The need for locally developed and owned data is an important one.

While most of these problems are well known and well understood, there is an increasing demand being made for donor organizations and research granting bodies to ensure that research is 'policy relevant'. Such a strategic aim often assumes that good science will easily lead to better public policy. In fact, the relationship between research and the results of scientific inquiry and the development of better public policy can actually be very weak. An exhaustive inquiry led by IDRC into how policy and research are intertwined found that the design of research to influence policy rarely has an impact. Rather, less tangible factors such as policy champions, 'windows of opportunity' and unforeseen change can have a more direct impact on public policy debates. It is more likely that research will contribute to change through a circuitous route rather than a direct one. The question then is really how to make research most relevant to local governments. Or, how to direct research from the outset in order to make it as useful as possible when it is complete. Our experience suggests that this is a much more 
challenging task than most researchers assume but that there are several avenues to make it happen:

1) Researchers need to be strategic political thinkers: The challenge for researchers is to be ready with the data and information that may suddenly be required for policy development. This is an art as much as a science and requires a keen eye to identify where innovation can be found. It also helps to have a sense of needs and priorities from a political standpoint. Local governments do not have the luxury to spend years designing and implementing programs, and are required to respond quickly when crises or opportunities arise.

2) Speak and understand their language: Economic arguments carry weight when proposing policy options. Convincing local government of the economic value of specific policy programs is one way to feed public policy debates. This requires research on the costs of inaction, for example, when tackling issues associated with pollution and the environment. Health risks are another driver - for instance, when citizens are at risk, local government policy tends to react and sometimes in a knee jerk fashion. A good example is local government policy on urban agriculture, an activity with many benefits that is often banned based on exaggerated fears of health risks. Peer pressure is also a notable way to convince policy actors to be innovative. No mayor or council wishes to be seen as a laggard when compared with their peers.

3) Geography matters: Most cities no longer fit within the administrative geography set up by colonial authorities. Reform to encourage metropolitan forms of governance that join disparate local governments in a cohesive fashion is a step forward. Research on the fiscal effectiveness of such metropolitan governance as well as the environmental and economic value of 'city regions' will be a key area of work in the near future.

4) Communicate! Responsibility also rests with researchers to become better communicators and to learn how to work with media. Many researchers fail in communicating what they do and know, and the end result is that research remains in the ivory tower. The assumption should not be made that learning from research is obvious. Messages need to be tailored and communication strategies clearly defined. Workshops are the standard venue to share learning but while they are useful, more is needed. Straightforward and categorical language is essential. For example, training scientists on 
how to explain their research in 3-minutes (probably the amount of time they will have to influence a mayor) can encourage precision and effectiveness. Researchers can also sometimes fail to understand the varied power and responsibility of the civil service: policy is a combination of elected officials and the city staff - technocrats, engineers, health professionals etc., that are working on day to day implementation of city programs.

Other lessons about the mechanics of bridging research policy can be extracted from the FCRI. First of all, where researchers are on the 'outside' of local government it is much more difficult to influence policy. Two options to address this include creating special research-oriented units housed within local governments, for instance an anti-poverty cell. A second is to cross-appoint staff between local universities and the city government. This institutional linkage can encourage mutually useful research programs, not to mention the possibility of students developing a better appreciation of the realities of local government. Cross appointments have been attempted in Kampala, Uganda and Rosario, Argentina with a fair degree of success.

The 'Commonwealth Vision' of local government is a key effort to harmonize an approach to increasing the effectiveness and accountability of governments. Challenges do remain. For one, the Commonwealth is diverse and local governments are subject to very different cultural and economic contexts. Local governments also vary in the responsibility afforded to them by their national governments, and while this is not an insignificant challenge, local governments will continue to be at the forefront of service delivery. In the context of decentralization, they are likely to continue to be delegated authority (but not necessarily the financial wherewithal) to manage these services. Research can not only provide the information and data required to build better policy, but can also be an avenue through which to build local government capacity to improve the effectiveness of its responses. 